\title{
A JUSTICIABILIDADE DOS DIREITOS HUMANOS COMO FORMA DE SUPERAÇÃO DA VIOLÊNCIA INSTITUCIONAL
}

\author{
${ }^{1}$ Manuel Maria Antunes de Melo
}

\section{RESUMO}

Tematiza-se a violência institucional sob o paradigma da modernidade ou da pósmodernidade e como superá-la por meio da justiciabilidade dos direitos humanos. Desde o ponto de vista da teoria abrangente das instituições de Karl-Otto Apel (2000), procura-se entender como a fragmentação cultural e a gradativa perda de legitimidade da instâncias estatais e da sociedade civil organizada contribuem para o vertiginoso crescimento da violência institucional, reproduzindo abusos e preconceitos incorporados no seu funcionamento natural, desafiando o ideal aristotélico de viver bem, para e com os outros, em instituições justas.

Palavras-chave: Direitos humanos; Violência institucional; Justiciabilidade.

\section{THE JUSTICIABILITY OF HUMAN RIGHTS AS A WAY OF OVERCOMING INSTITUTIONAL VIOLENCE}

\begin{abstract}
It is discussed the institutional violence in the paradigm of modernity or postmodernity, and how to overcome it through the justiciability of human rights. From the standpoint of KarlOtto Apel's comprehensive theory of institutions (2000), one seeks to understand how cultural fragmentation and the gradual loss of legitimacy of state bodies and organized civil society contribute to the rapid growth of institutional violence, Reproducing abuses and prejudices embedded in its natural functioning, challenging the Aristotelian ideal of living well, for and with others, in just institutions.
\end{abstract}

Keywords: Human rights; Institutional violence; Justiciability.

\footnotetext{
${ }^{1}$ Especialista em Direito Processual Civil, Mestrando em Direito pela Universidade Católica de Petrópolis UCP/RJ, Rio de Janeiro, (Brasil). Juiz de Direito Licenciado do TJ/PB. E-mail: juizmanuelmaria@gmail.com
} 


\section{INTRODUÇÃO}

A violência, em qualquer de suas formas, seja ela física, moral e/ou psíquica, explícita ou velada, de origem religiosa ou laica, de gênero, raça, cor ou etnia, gratuita ou egoística, constitui a antítese dos direitos humanos na medida em que consubstancia inescusável negação da dignidade da pessoa humana.

À ela se contrapõe o direito fundamental à segurança, previsto no art. $3^{\circ}$ da Declaração Universal dos Direitos Humanos $(1948)^{2}$; no art. $9^{\circ}, \mathrm{n}^{\circ} 1$, do Pacto Internacional de Direitos Civis e Políticos $(1966)^{3}$; no art. $7^{\circ}, n^{\circ} 1$, da Convenção Americana sobre Direitos Humanos $(1969)^{4}$ e, finalmente, no art. $5^{\circ}$, caput, da Constituição Federal Brasileira $(1988)^{5}$.

Cabe ao Estado (art. 144 da $\mathrm{CF} / 88)^{6}$, como destinatário do monopólio da força (WEBER, 1963, p. 124-125), garantir a integridade física, moral e psíquica de seus cidadãos, mediante o uso do aparelhamento institucional de que dispõe, uma vez que:

Os direitos fundamentais, ao contrário das Constituições anteriores, estão contidos no início da Constituição, o que denota a preocupação do legislador constituinte em vê-los assegurados e efetivados pelo Estado. Em razão disso, há de considerar a segurança pública como direito fundamental, por isso, exigível uma abordagem mais específica. (RIO, 2013, p. 12, grifo nosso).

Acontece, porém, que a violência, em suas mais variadas expressões, provém, em muitos casos, dos próprios órgãos estatais encarregados do sistema de segurança, o que constitui um grave dilema onde o cidadão fica completamente à mercê de seus próprios algozes, como bem retratado no seguinte excerto de texto publicado pela filósofa Alba Zaluar:

A denúncia da repressão policial, muito embora importante para tornar públicas as
inúmeras violações dos direitos civis ou fundamentais, presentes na Constituição
Brasileira de 1988, tomou tanto investimento que barrou em certa medida a
formulação de projetos de reforma das instituições. Criou-se, assim, um círculo
vicioso das violações de direitos e da escalada da violência pela inércia institucional
e a cegueira dos que elaboram políticas de segurança que não resolvem os problemas
estruturais das principais instituições que as levam a efeito. O monopólio tradicional
da polícia repressiva, que não presta contas aos contribuintes cidadãos nem se livra
dos mecanismos perversos que a faz privilegiar o pobre como alvo de sua
investigação e castigo, mas também não investe na investigação e na eficiência na

\footnotetext{
2 "Todo ser humano tem direito à vida, à liberdade e à segurança pessoal”.

3 “Artigo 9: [...]: 1. Toda pessoa tem direito à liberdade e à segurança pessoais. [...]"

4 “Artigo $7^{\circ}$ - Direito à liberdade pessoal: 1 . Toda pessoa tem direito à liberdade e à segurança pessoais".

5 “Art. $5^{\circ}$ Todos são iguais perante a lei, sem distinção de qualquer natureza, garantindo-se aos brasileiros e aos estrangeiros residentes no País a inviolabilidade do direito à vida, à liberdade, à igualdade, à segurança e à propriedade [...]".

6 "Art. 144. A segurança pública, dever do Estado, direito e responsabilidade de todos, é exercida para a preservação da ordem pública e da incolumidade das pessoas e do patrimônio [...]”.
} 
resolução dos crimes que mais afetam a população pobre, arrasta-nos para o poço cada vez mais fundos da violência societária e institucional irremediavelmente atreladas. Só depois de desfeito este nó pode-se pensar numa polícia comunitária que sirva a uma população local e preste contas de seus atos a ela. (ZALUAR, 2005, p. 19-20).

O presente artigo pretende contribuir para uma reflexão sobre a violência institucional e sua superação pela justiciabilidade dos direitos humanos. Para tanto se buscará: 1.) discorrer sobre a violência institucional e sua implicação com os direitos humanos; 2.) abordar a justicialidade dos direitos humanos como forma de superação da violência institucional $e$ 3.) verificar como se dá a proteção dos direitos humanos no âmbito do Sistema Interamericano de Direitos Humanos.

Ele resulta de pesquisa descritiva realizada no Programa de Pós Graduação stricto sensu - Mestrado em Direito da Universidade Católica de Petrópolis (UCP/RJ), com emprego dos métodos de abordagem dialético e sistêmico, utilizando-se as técnicas de análise documental e pesquisa bibliográfica.

\section{A violência institucional e sua implicação com os direitos humanos}

Ao propósito de se discorrer sobre a violência institucional se impõe, antes de mais nada, encontrar uma definição que possa fixar seus devidos contornos. E, nada melhor para este fim do que se começar conceituando o que se deve entender por instituições.

Neste sentido, buscando subsídios na teoria abrangente das instituições, proposta pelo filósofo e sociólogo alemão Arnold Gehlen (1956), Karl-Otto Apel, num texto denominado A "filosofia das instituições" de Arnold Gehlen e a Metainstituição da Linguagem, publicado em 1973, assim expõe com absoluta propriedade:

[...] instituição em sentido amplo toda cristalização e autonomização de nosso trato comportamental com o mundo exterior e com os outros, adequadas para atribuir a nosso comportamento uma consistência externa capaz de estabelecer compromissos. Nesse sentido, uma instituição é até mesmo uma troca de correspondência entre diversas pessoas; ou, para mencionar um exemplo mais elementar ainda, a maneira especializada que a elaboração de um artefato exige, e que acaba por se transformar em um fim de si mesma. (APEL, 2000, p. 233).

Já para Émile Durkheim a instituição social nada mais é do que um mecanismo de proteção da sociedade que consiste num conjunto de regras e procedimentos padronizados socialmente, reconhecidos, aceitos e sancionados pela mesma sociedade, cuja importância estratégica é manter a organização do grupo e satisfazer as necessidades dos indivíduos que dele participam. As instituições são, portanto, conservadoras por essência, quer seja a 
família, a escola, o governo, a polícia ou qualquer outra, elas agem fazendo força contra as mudanças, pela manutenção da ordem. (DURKHEIM, apud ARON, 1982, p. 297-374).

Instituições são, portanto, organizações ou mecanismos sociais que controlam o funcionamento da sociedade e, por conseguinte, dos indivíduos, refletindo experiências quantitativas e qualitativas dos processos socioeconômicos. Elas compreendem um amplíssimo escopo de dispositivos como a linguagem, os ritos, a técnica, a magia, o sistema jurídico, a família, a escola, os partidos políticos, a imprensa, a prisão, o Estado, a igreja, etc.

Organizadas sob o escopo de regras e normas, visam à ordenação das interações entre os indivíduos e entre estes e suas respectivas formas organizacionais, assumindo papel fundamental no processo de socialização, levando cada indivíduo a tornar-se membro da sociedade.

Devido ao papel fundamental que as instituições exercem na organização, desenvolvimento e controle da própria sociedade, é natural que surjam conflitos na esfera da complexa dinâmica que se estabelece entre ela e os indivíduos, pois cada instituição é dotada de um ethos específico que tem por função estabilizar e orientar o agir humano, sendo assim, em última instância, um mecanismo de substituição dos instintos dos quais o homem se libertou ao longo do processo de hominização. (DURKHEIM, apud ARON, 1982, p. 363).

Ainda a propósito da violência que brota no seio das instituições, destaque-se a problematização trazida à lume por Ricoeur, quando discorre sobre a universalidade versus historicidade dos direitos humanos: porque se não pode ficar no nível ético do querer viver bem, para e com os outros, em instituições justas?

“[...] A razão é que a vida em sociedade abre um espaço imenso e às vezes aterrorizante a conflitos de todos os tipos que afetam todos os níveis dos relacionamentos humanos em termos de interesses, crenças, convicções. Ora, esses conflitos tendem a expressar-se por violências de todos os tipos, que vão do assassinato à traição da palavra dada. (RICOEUR, 2008, p. 266).

Em idêntico sentido e partindo do pressuposto de que as instituições são o espelho da própria sociedade de cujo seio emergem, Balestra pontua que:

[...] Las instituciones marcan, contienen, limitan la anatomia de uma comunidad. Esa comunidad no es un fresco egípcio sino un cuerpo vivo. La vida de esa sociedad no sólo gravita sobre sus instituciones sino que transmite la totalidad de sus cualidades y falencias sobre ellas. Por lo tanto, las instituciones tienen vida. Nacieron como respuesta a una necessidad. (BALESTRA, 2007, p. 47-48). 
Logo, a violência institucional é aquela que nasce e se desenvolve no âmbito de uma instituição, seja ela familiar, educacional, religiosa, civil, estatal ou simplesmente representativa, devendo ser compreendida, no contexto da modernidade líquida, como:

[...] a contrapartida de nossas liberdades individuais e de nossos mercados não regulamentados, a dimensão externa de nossas decisões econômicas, um derivado de nossos estilos de vida mutáveis e de nossa cultura de consumo desenfreado, um efeito de nossa preferência geral por um tipo de controle social não autoritário. (GARLAND, 1999, p. 62).

Em matéria de proteção de direitos e valores cultivados por uma sociedade, as instituições sociais assumem, efetivamente, esse papel fundamental, razão pela qual Calmon de Passos afirma que a proteção da liberdade - e, portanto, dos demais direitos fundamentais - se assenta mais na "institucionalização do dever" do que na jurisdicização das condutas:

\begin{abstract}
Dessa verdade inconteste inferimos que a garantia de nossa liberdade repousa muito menos no que nos é prometido em proclamações político-jurídicas e muito mais, senão quase que exclusivamente, na institucionalização social de limites postos à liberdade dos indivíduos, isto é, das não-liberdades sociais. Daí a falácia das proclamações exclusivamente jurídicas de liberdades, quando falta a prévia institucionalização social da não-liberdade correspectiva ou inexiste a vontade social e política de institucionalizá-la. (CALMON DE PASSOS, 2011, p. 856-858).
\end{abstract}

Em artigo intitulado O Novo Paradigma da Violência, Wieviorka (1997, p. 18) enfoca o papel central do Estado na análise clássica da violência, notabilizado na célebre fórmula de Max Weber (1919), segundo a qual o Estado "só pode ser definido sociologicamente pelo meio específico que lhe é próprio, assim como a todo grupo político, a saber, a violência física $[\ldots]$ ”.

Abordando o tema, todavia, sob o paradigma da modernidade ou da pósmodernidade, Wieviorka (1997, p. 19-21) atribui à fragmentação cultural o processo de perda gradativa, pelo Estado, do monopólio legítimo da violência física, gerando a ideia de um declínio-superação da concepção de Estado-nação, de onde a violência surge e se desenvolve em meio às carências do próprio Estado. Adverte, ademais, que:

[...] o Estado, pela intervenção de seus agentes, pode praticar ou encobrir uma violência ilegítima, contrária ao seu discurso oficial, como acontece em países democráticos onde existe a tortura, os abusos policiais ou militares de todo o gênero, ou ainda a delegação do uso da força a atores privados que a exercem em proveito de seus interesses [...]. (WIEVIORKA, 1997, p. 19).

Para Chesnai (1999, p. 57), o declínio das instituições tem papel preponderante na análise das causas da violência, cuja fraqueza e descrédito estão na gênese do crescimento vertiginoso da violência no Brasil, já que a Polícia Civil e o Sistema Penitenciário não são respeitados, a Policia Militar é considerada violenta, facilmente exposta ao ridículo e impune, 
já que protegida por seus próprios tribunais; a Justiça é lenta, ineficaz e inacessível ao cidadão devido aos elevados honorários dos advogados, enquanto seus juízes não estão devidamente preparados para lidar com os crimes financeiros ou de "colarinho branco".

Destaca, ainda, que a Igreja Católica encontra-se dividida, enfraquecida e afastada do povo, abrindo espaço para seitas cada vez mais numerosas, ricas e poderosas, enquanto os meios de comunicação, liderados pela televisão, prodigalizam-se pela apologia ao dinheiro e à violência. Monopolizado pelos produtores, o império da mídia bestializa os telespectadores com uma enxurrada de imagens sangrentas, banalizando a violência. (CHESNAI, 1999, p. 59).

Na mesma linha defendida por Wieviorka (1997), Chesnai sustenta que o crescimento da violência reflete, em primeiro lugar, a crise do Estado, pois:

Só nestas circunstâncias há deterioração do Estado-Nação, enquanto representante do bem comum, repositório legítimo do direito e da força em nome do respeito à lei. Exatamente como acontece na Itália, na Rússia, na Colômbia, em Uganda ou no Zaire, onde as máfias locais tomam o poder e arruínam a credibilidade política das nações [...]. (CHESNAI, 1999, p. 60).

Alba Zaluar também destaca que o ciclo vicioso de violações sistemáticas de direitos fundamentais, levadas a cabo pelas próprias instituições estatais, agrava o caótico estado de violência social que, em princípio, deveriam combater, na medida em que:

[...] O monopólio tradicional da polícia repressiva, que não presta contas aos contribuintes cidadãos nem se livra dos mecanismos perversos que a faz privilegiar o pobre como alvo de sua investigação e castigo, mas também não investe na investigação e na eficiência na resolução dos crimes que mais afetam a população pobre, arrasta-nos para o poço cada vez mais fundos da violência societária e institucional irremediavelmente atreladas. Só depois de desfeito este nó pode-se pensar numa polícia comunitária que sirva a uma população local e preste contas de seus atos a ela. (ZALUAR, 2005, p. 19-20).

Em relatório produzido pelo Instituto Latino-Americano das Nações Unidas para Prevenção do Delito e Tratamento do Delinquente, são trazidos dados alarmantes sobre a violência praticada no âmbito das instituições públicas, notadamente nas de segurança (ILANUD, 2016), demonstrando o quão distante o Brasil ainda está no quesito promoção e proteção dos direitos humanos mais elementares, pois torturas, grupos de extermínio, negligência nos abrigos e descaso do Poder Judiciário são práticas que continuam acometendo jovens em todo o país, inclusive com torturas e execuções extrajudiciais, na esteira do que se extrai do relatório do UNICEF (2006):

Sin embargo, está claro que la violencia contra los niños y niñas en los centros de detención es un problema generalizado muy grave. En su 37 sesión, el Comité de 
Derechos del Niño dijo que tenía motivos de preocupación sobre los procedimientos y la protección de los niños y niñas en poder del sistema judicial en el Brasil, entre otros países, ya que había informes sobre tortura y asesinatos extrajudiciales en los establecimientos penitenciarios.

Compreende-se, portanto, que a violência institucional constitui um dos principais obstáculos para se chegar a um estágio aceitável de respeito aos direitos fundamentais do homem, erigindo-se em verdadeiro bloqueio para se alcançar o ideal aristotélico de viver bem, para e com658 os outros, em instituições justas (RICOEUR, 2008, p. 261-280). E, para se entender a violência institucional, como fenômeno social que é, implica em perquirir sua causa eficiente, identificar o fenômeno antecedente que o produz, necessariamente.

Desta forma, as causas da violência institucional devem ser procuradas no meio social, já que a estrutura da sociedade constitui a causa dos fenômenos sociais que a caracterizam, pois "É na natureza da própria sociedade que devemos procurar a explicação da vida social [...]", haja vista que "A origem primordial de todo processo social de alguma importância deve ser procurada na constituição do meio social interno [...]” (DURKHEIM, 1956, p. 101 e 111, respectivamente), de onde se concluir que a violência cometida no âmbito das instituições públicas nada mais é do que a reprodução espontânea, uma extensão daquela que se desenvolve no âmbito das demais instituições sociais, cuidando-se, assim, de fenômeno tolerado ou suportado, percebido quase como que inscrito no funcionamento normal da sociedade (WIEVIORKA, 1997, p. 10), o que torna um problema de Estado, de difícil e incerta solução, já que pressupõe uma mudança de cultura da própria sociedade e, por extensão, dos agentes estatais correspondentes.

A violência institucional, como fenômeno inexorável da vida em sociedade (RICOEUR, 2008, p. 266), fomentada pelo modo de vida da pós-modernidade, que se caracteriza pelo consumismo, pelo imediatismo e pelo individualismo (GARLAND, 1999, p. 62), produz um efeito perverso no qual as pessoas alijadas desse processo são colocadas à margem da sociedade de consumo, culminando na criminalização de grande parcela de jovens pobres, negros e analfabetos funcionais, conforme demonstra o último senso realizado pelo Ministério da Justiça (BRASIL, 2016).

De fato, no item 3.2. Perfil e situação das pessoas privadas de liberdade no sistema prisional, o censo destaca: a) Faixa etária: 30,12\% dos presidiários estão entre 18-24 anos e $24,96 \%$ na faixa de 25-29 anos, totalizando 55,07\%, enquanto a população brasileira nessa escala etária é de apenas $18,19 \%$; b) Raça, cor ou etnia: $61,67 \%$ da população carcerária 
$(+1 / 3)$ é negra, preta ou parda, enquanto na formação da população brasileira esse segmento representa apenas 53,63\%; c) Escolaridade: 75,08\% dos presidiários possuem, apenas, o ensino fundamental completo, o que implica dizer que $3 / 4$ do contingente prisional é integrado por alfabetizados funcionais.

O senso demonstra, ainda, que a predominância do contingente prisional é do sexo masculino $(94,2 \%)$, solteiro (57\%) e com um ou mais filhos $(59 \%)$. O tipo penal que lidera o ranking é o de tráfico de drogas (28\%), seguido pelo de roubo (25\%) e o de furto (13\%).

Tais dados comprovam, a mais não poder, que o modo de vida egoístico, típico da pós-modernidade ou da modernidade líquida, fomenta uma patologia social que compromete o ideal aristotélico de viver bem, com e para os outros, em instituições justas, emergindo a necessidade da intervenção de um terceiro, representado pela a lei, pelos códigos, juízes e tribunais, enfim, a Justiça, cuja tarefa primordial é proferir uma palavra de justiça numa situação concreta, transferindo o conflitos do nível da violência irracional para o campo da linguagem e do discurso. (RICOEUR, 2008, p. 254-257).

\section{A justiciabilidade dos direitos humanos como forma de superação da violência institucional}

A Declaração Universal dos Direitos Humanos, aprovada pela Assembleia Geral das Nações Unidas de 10 de dezembro de 1948, estatuiu, em seu art. VIII, que:

Todo homem tem direito a receber dos tribunais nacionais competentes proteção efetiva contra os atos que violem os direitos fundamentais que lhe sejam reconhecidos pela Constituição ou pela lei.

A Convenção Americana sobre Direitos Humanos, aprovada na Conferência de San José da Costa Rica ${ }^{7}$, de 22/11/1969, ao seu tempo, trata da proteção judicial dos direitos fundamentais no art. $25, \mathrm{n}^{\circ} 1$, dispondo que:

Toda pessoa tem direito a um recurso simples e rápido ou a qualquer outro recurso efetivo, perante os juízes ou tribunais competentes, que a proteja contra atos que violem seus direitos fundamentais reconhecidos pela Constituição, pela lei ou pela presente Convenção, mesmo quando tal violação seja cometida por pessoas que estejam atuando no exercício de suas funções oficiais.

\footnotetext{
${ }^{77}$ O Brasil aderiu à Convenção (CIDH) em 25-9-1992, promulgando-a pelo Decreto $\mathrm{n}^{\circ}$ 678, de 6/11/92, enquanto a jurisdição obrigatória da Corte Interamericana de Direitos Humanos (CIDH) foi reconhecida, para fatos ocorridos a partir do reconhecimento, pelo Decreto Legislativo $\mathrm{n}^{\circ}$ 89, 03 de dezembro de 1998, sendo esse reconhecimento promulgado pelo Decreto $\mathrm{n}^{\mathrm{o}}$ 4.463/02, publicado em 11/11/2002. (COMPARATO, 2010, p. 379).
} 
Desta forma, nos tempos atuais, o desafio que se coloca em relação aos direitos do homem não mais reside em sua justificação, mas sim na proteção que lhe é dispensada, isto é, uma questão política e já não mais apenas filosófica. (BOBBIO, 2004, p. 23).

A problemática da proteção judicial dos direitos humanos nos remete ao julgamento do memorável caso Marbury v. Madison, quando a Suprema Corte dos Estados Unidos da América (1803) estabeleceu o princípio da justicialidade de todo e qualquer direito fundado em norma constitucional. Assim, como os direitos humanos passaram a fazer parte do elenco de direitos fundamentais nas diversas Constituições Nacionais, reconheceu-se que a primeira e fundamental garantia desses direitos era a de natureza judicial. (COMPARATO, 2010, p. 125-127).

Essa garantia, segundo Silva (2008, p. 252), encarna o mais importante dos direitos fundamentais, exatamente porque é através do direito de ação ao Poder Judiciário que se asseguram e efetivam, na prática, todos os demais direitos garantidos pelo ordenamento jurídico, sejam eles de natureza fundamental ou não.

Neste passo, o Direito Constitucional Brasileiro, abandonando a tradição francesa, aproximou-se do pragmatismo do civil law, segundo o qual o progresso na proteção jurídica da pessoa humana provém mais das garantias institucionais, sobretudo das instâncias judiciais, do que das simples declarações de direitos (COMPARATO, 2010, p. 101).

Para Alexy, a completa possibilidade de arguição perante o Judiciário, que atinge a totalidade das normas constitucionais, é um dos tesouros da Lei Fundamental Alemã, razão pela qual:

\footnotetext{
A todas as tentativas de suavizar o problema da colisão [de direitos fundamentais] pela eliminação da justicialidade deve opor-se com ênfase. [...] A primeira decisão fundamental para os direitos fundamentais é, por conseguinte, aquela para a sua força vinculativa jurídica ampla em forma de justicialidade. (ALEXY, 2011, p. 63, grifo nosso).
}

Por conseguinte, a proteção e a defesa dos direitos humanos, no plano interno, está imbricada com a garantia que lhe é assegurada pelo aparato judicial respectivo, consubstanciando-se, no Direito Constitucional Brasileiro, na cláusula de universalidade da jurisdição, estatuída no art. $5^{\circ}$, inc. XXXV, CF/88.

A experiência institucional brasileira demonstra, a mais não poder, a íntima relação existente entre proteção dos direitos fundamentais, divisão de poderes e, em especial, independência judicial, na medida em que: 
[...] sem divisão de poderes e, em especial, sem independência judicial, isto [defesa dos direitos humanos] não passa de uma declaração de intenções. Por isso, [...] os direitos humanos só podem ser realizados quando limitam o poder do Estado, quando o poder estatal está baseado em uma ordem jurídica que inclui a defesa dos direitos humanos (KRIELE, 1980, p. 149-150).

De fato. Sem separação de poderes e independência judicial, o catálogo de direitos fundamentais de uma Constituição não passa de mera ficção jurídica, como bem demonstra a experiência recente do Brasil, onde os direitos civis e políticos, sob o regime militar pós-64, foram praticamente abolidos, já que o Poder Judiciário, responsável por sua garantia, teve sua esfera de atuação drasticamente restringida pelo regime de exceção que, dentre as muitas violências praticadas pelo $\mathrm{AI}^{\circ}{ }^{\circ}$, permitiu a suspensão da revisão judicial dos atos de governo, abrindo caminho para a prática das maiores violências, sem qualquer freio ou controle judicial. (CARVALHO, 2012, p. 193).

Digno de nota também é o caso do Chile, relativamente ao ocorrido com a acción de protección, correspondente ao habeas corpus, onde dos 10.000 a 12.000 amparos impetrados entre 1973 - 1990, no sob os auspícios da ditadura militar do Gen. Augusto Pinochet, não prosperou mais de $1 \%$ do total, o que é estarrecedor quando se tem em mente o histórico de maciça violação dos direitos humanos no País Transandino. (MORELLO, 2011, p. 719-738).

Reconhece-se, portanto, o papel fundamental do Poder Judicial para assegurar a promoção e a proteção dos direitos humanos contra todas as formas possíveis de violação, estejam eles positivados no texto constitucional ou não, tendo em vista cláusula aberta adotada pelo art. $5^{\circ}, \S 2^{\circ}$, da $\mathrm{CF} / 88^{8}$, identificando-se uma relação direta entre a independência judicial e a efetiva de proteção dos direitos fundamentais.

Acontece, porém, que as violações dos direitos humanos são praticadas, também, no âmbito das complexas estruturas judiciárias, situação em que se reclama a intervenção de organismos internacionais de promoção e proteção dos direitos humanos; no caso do Brasil, o Sistema Interamericano de Direitos Humanos.

\section{Proteção dos direitos humanos no âmbito do Sistema Interamericano de Direitos Humanos}

\footnotetext{
8 “Art. $5^{\circ}[\ldots] \S 2^{\circ}$ Os direitos e garantias expressos nesta Constituição não excluem outros decorrentes do regime e dos princípios por ela adotados, ou dos tratados internacionais em que a República Federativa do Brasil seja parte".
} 
O Sistema Interamericano de Direitos Humanos é composto por dois órgãos previstos no art. 33 da Convenção Americana sobre Direitos Humanos (CADH), sendo eles: a) a Comissão Interamericana de Direitos Humanos, denominada a Comissão; e b) a Corte Interamericana de Direitos Humanos, denominada Corte IDH.

A Comissão tem a função principal de promover a observância e a defesa dos direitos humanos $(\mathrm{CADH}$, art. 41) e, no exercício de seu mandato, submeter um caso à jurisdição contenciosa da Corte. Além da Comissão, só os Estados-partes da Convenção podem provocar a jurisdição da Corte (CADH, art. 61.1).

O Brasil aderiu à Convenção em 25/09/1992, promulgando-a pelo Decreto n ${ }^{\circ} 678$, de 6/11/92, enquanto a jurisdição obrigatória da Corte IDH foi reconhecida, para fatos ocorridos a partir do reconhecimento, pelo Decreto Legislativo $\mathrm{n}^{\circ} 89,03$ de dezembro/89 9 . (COMPARATO, 2010, p. 379).

Todavia, segundo consta do endereço eletrônico do Departamento de Direito Internacional da Organização do Estados Americanos (OEA), a data de aceitação da jurisdição da Corte IDH, em relação ao Brasil, conta somente a partir de 10 de dezembro de 1998, data do depósito do correspondente instrumento de ratificação:

El Gobierno de la República Federativa de Brasil declara que reconoce, por tiempo indeterminado, como obligatoria y de pleno derecho, la competencia de la Corte Interamericana de Derechos Humanos, en todos los casos relacionados con la interpretación o aplicación de la Convención Americana [sobre] Derechos Humanos, de conformidad con el artículo 62 de la misma, bajo reserva de reciprocidad y para hechos posteriores a esta Declaración. (OEA, 2016).

Assim, com base no art. 62.1 da CADH e no princípio da irretroatividade previsto no art. 28 da Convenção de Viena sobre o Direito dos Tratados, a Corte IDH não pode exercer sua competência contenciosa para aplicar a Convenção e declarar uma violação a suas normas quando os fatos alegados ou a conduta do Estado, que puderem implicar sua responsabilidade internacional, forem anteriores ao dito reconhecimento da competência da Corte, uma vez que:

A efectos de determinar si tiene o no competencia para conocer un caso o un aspecto del mismo, de acuerdo con el artículo 62.1 de la Convención Americana, el Tribunal debe tomar en consideración la fecha de reconocimiento de la competencia por parte del Estado, los términos en que el mismo se ha dado y el principio de

\footnotetext{
9 “Art. $1^{\circ}$ É aprovada a solicitação de reconhecimento da competência obrigatória da Corte Interamericana de Direitos Humanos em todos os casos relativos à interpretação ou aplicação da Convenção Americana de Direitos Humanos para fatos ocorridos a partir do reconhecimento, de acordo com o previsto no parágrafo primeiro do art. 62 daquele instrumento internacional".
} 
irretroactividad, dispuesto en el artículo 28 de la Convención de Viena sobre el Derecho de los Tratados de 1969 (Corte IDH, 2010).

Não obstante, a jurisprudência da Corte IDH tem estabelecido que os atos de caráter contínuo ou permanente se estendem durante todo o tempo no qual o fato continua mantendose em desconformidade com a obrigação internacional. Neste sentido, a Corte recorda que o caráter contínuo ou permanente do desaparecimento forçado de pessoas tem sido reconhecido de maneira reiterada pelo Direito Internacional dos Direitos Humanos, segundo o qual o ato de desaparecimento e sua execução se iniciam com a privação da liberdade da pessoa e a subsequente falta de informação sobre o seu destino, permanecendo como tal enquanto não se conheça o paradeiro da pessoa desaparecida ou até que os fatos sejam completamente esclarecidos. Por conseguinte, a Corte se declara competente para analisar acusações de desaparecimento forçado de vítimas a partir do reconhecimento de sua competência contenciosa, ainda que o fato tenha se iniciado anteriormente ao dito reconhecimento (Corte IDH, 2010).

A sentença da Corte é definitiva e inapelável (CADH, art. 67). Ela tem competência para conhecer de qualquer caso, relativo à interpretação e aplicação das disposições da Convenção, que lhe seja submetido, desde que os Estados-partes no caso tenham reconhecido ou reconheçam a referida competência, seja por declaração especial, seja por convenção especial. (CADH, art. 61.3).

Dentre as penalidades aplicáveis, a Corte pode impor ao Estado que: a) assegure ao prejudicado o gozo do seu direito ou liberdade violados; b) sejam reparadas as consequências da medida ou situação que haja configurado a violação desses direitos, bem como o pagamento de indenização justa à parte lesada.

Em casos de extrema gravidade e urgência, e quando se fizer necessário evitar danos irreparáveis às pessoas, poderá a Corte, nos assuntos de que estiver conhecendo, tomar as medidas provisórias que considerar pertinentes. Se se tratar de assuntos que ainda não estiverem submetidos ao seu conhecimento, poderá atuar a pedido da Comissão. (CADH, art. $63, n^{\circ}$ s 1 e 2).

De outra senda, de acordo com os artigos 44 ou 45 da CADH, para que uma petição ou comunicação apresentada seja admitida pela Comissão, será necessário, dentre outros requisitos, que hajam sido interpostos e esgotados os recursos da jurisdição interna, de acordo com os princípios de Direito Internacional geralmente reconhecidos. 
Entrementes, uma objeção ao exercício da jurisdição da Corte, baseada na suposta falta de exaurimento dos recursos internos, deve ser apresentada durante a etapa de admissão do procedimento ante a Comissão $(\mathrm{CADH}$, art. 48). Ademais, não cabe à Corte, tampouco à Comissão, identificar, ex officio, quais são os recursos internos a esgotar, mas que corresponde ao Estado indicar, tempestivamente, os recursos internos que devem ser efetivamente esgotados (Corte IDH, 2010).

Advirta-se, ainda, que é necessário que o Estado não apenas especifique os recursos internos disponíveis, que não tenham sido esgotados, como também demonstre que estes recursos se encontravam efetivamente disponíveis, eram adequados, idôneos e efetivos aos fins colimados (Corte IDH, 2015).

\section{Conclusões}

A análise dos temas em questão permite concluir que a violência institucional, no Brasil, é um fenômeno social visto quase como inscrito no funcionamento normal da sociedade, razão pela qual é suportado ou tolerado, o que torna difícil a sua erradicação, já que pressupõe uma mudança de mentalidade dos próprios agentes estatais no que diz respeito à premente e inarredável necessidade de respeito aos direitos humanos.

Neste contexto, a justiciabilidade dos direitos humanos é fator decisivo para a superação da violência institucional, incrustrada na vida social e cultural do país, com larga aceitação no âmbito das instituições públicas e privadas. Para tanto, a cláusula pétrea que garante a separação de poderes e a independência judicial é fundamental no Estado Democrático de Direito, uma vez que a proteção dos direitos fundamentais e a independência do Poder Judiciário são temas indissociáveis, pois Cuando los jueces tienem medo no hay liberdades que resplandezcan, sabia enseñar Couture. (MORELLO, 2011, p. 728).

De outra senda, como a agressão aos direitos humanos pode partir das próprias instituições estatais encarregadas de sua proteção, inclusive judiciais, é de fundamental importância a inserção do Brasil no Sistema Interamericano de Direitos Humanos, onde as decisões da Corte IDH, para além de constituir um instrumento natural de pressão sobre as autoridades nacionais, na defesa dos direitos humanos, vem contribuindo para a fomentação de uma cultura de promoção e defesa dos direitos humanos, tanto no âmbito judicial quanto fora dele. 
Neste sentido, não obstante a restrição feita às inspeções da Comissão ${ }^{10}$, nos últimos doze anos o Brasil instituiu, fortaleceu e ampliou sua política na área de direitos humanos (MOURA, 2010, p. 244), aprovando, por meio da EC no 45/2004, denominada "Reforma do Judiciário", um conjunto de importantes medidas das quais destacam-se: a) a possibilidade de elevação dos tratados internacionais de direitos humanos à categoria de norma constitucional, quando aprovados pelo rito especial das emendas constitucionais $\left(\mathrm{CF} / 88\right.$, art. $\left.5^{\circ}, \S 3^{\circ}\right)$; b) a previsão do incidente de federalização do processo para os casos de grave violação dos direitos humanos $\left(\mathrm{CF} / 88\right.$, art. 109, $\left.\S 5^{\circ}\right)$; c) a criação do Conselho Nacional de Justiça, órgão encarregado de aperfeiçoar o funcionamento Poder Judiciário, com a consequente otimização da proteção judicial dos direitos fundamentais (CF/88, art. 92, inc. I-A); d) a adoção do princípio da razoável duração do processo, vedando a transformação da pessoa em objeto de processos judicias ou administrativos $\left(\mathrm{CF} / 88\right.$, art. $5^{\circ}$, inc. LXXVIII) $e$ e) sujeição do Brasil à jurisdição do Tribunal Penal Internacional a cuja criação tenha manifestado adesão (CF/88, $\left.\operatorname{art.} 5^{\circ}, \S 4^{\circ}\right)$.

Não obstante, o respeito aos direitos humanos, no Brasil, só será alcançado, em sua plenitude, quando a sociedade brasileira, no conjunto de suas complexas e, por vezes, antagônicas estruturas sociais ${ }^{11}$, internalizar o sentimento de que a dignidade do ser humano e de seus direitos iguais e inalienáveis, constitui o fundamento da liberdade, da justiça e da paz social, condição essencial do progresso e do desenvolvimento de melhores condições de vida para todos, aspirações estas que só germinam e frutificam num ambiente de liberdade, igualdade e fraternidade.

\footnotetext{
10 "El Gobierno de Brasil entiende que los Artículos 43 y 48, letra D, no incluyen el derecho automático de visitas e inspecciones in loco de la Comisión Interamericana de Derechos Humanos, las cuales dependerán de la anuencia expresa del Estado".

${ }^{11}$ Ensejando uma das características mais marcantes de nossa sociedade, qual seja, o "equilíbrio de antagonismos", na percuciente análise de Freyre (2003, p. 116).
} 


\section{REFERÊNCIAS BIBLIOGRÁFICAS}

ALEXY, Robert. Constitucionalismo Discursivo. Organização e Tradução Luis Afonso Heck. Porto Alegre: Livraria do Advogado, 2011.

APEL, Karl-Otto. Transformação da Filosofia I: Filosofia Analítica, Semiótica, Hermenêutica. Tradução Paulo Astor Soethe. São Paulo: Edições Loyola, 2000.

ARON, Raymond. As Etapas do Pensamento Sociológico. Coleção Sociedade Moderna, vol. 6. Brasília: Editora UNB, 1982.

BALESTRA. René. La Calidad Institucional y el Hombre Común. In Calidad Institucional o Decadencia Republicana. Buenos Aires: Lajouane - Academia Nacional de Ciencias Morales y Políticas, 2007.

BOBBIO, Norberto. A Era dos Direitos. Tradução de Carlos Nelson Coutinho. Rio de Janeiro: Elsevier, 2004.

BRASIL. Ministério da Justiça. Departamento Penitenciário Nacional (DEPEN). Levantamento Nacional de Informações Penitenciárias INFOPEN - Dezembro/2014. Brasília/DF: 2016. Disponível em: <http://www.justica.gov.br/seus-direitos/politicapenal/infopen_dez14.pdf/@@download/file>.Acessado em: 19.dez.2016.

CALMON DE PASSOS, J.J. Tutela Jurisdicional das Liberdades. In Instrumentos e Garantais de Proteção. Organização Flávia Piovesan e Maria Garcia. São Paulo: RT, 2011, Coleção Doutrinas Essenciais, volume. 5.

CARVAlhO, José Murilo. Cidadania no Brasil: O Longo Caminho. Rio de Janeiro: Civilização Brasileira, 2012.

CEIA. Eleonora Mesquita. A Jurisprudência da Corte Interamericana de Direitos Humanos e o Desenvolvimento da Proteção dos Direitos Humanos no Brasil. Rio de Janeiro: R. EMERJ, v. 16, n. 61, jan/mar: 2013.

CHESNAIS, Jean Claude. A violência no Brasil: causas e recomendações políticas para sua prevenção. Tradução Ida Maria Rebelo Pereira. In: MONTEIRO, Maria da Conceição N. (Org.). Ciência e Saúde Coletiva. Rio de Janeiro: 1999. n. 4. p.53-69.

COMPARATO, Fábio Konder. A Afirmação Histórica dos Direitos Humanos. São Paulo: Saraiva, 2010, $7^{\mathrm{a}}$ edição, revista e atualizada.

CORTE INTERAMERICANA DE DERECHOS HUMANOS (Corte IDH). Caso Ximenes Lopes vs. Brasil. Sentença de 4 de julho de 2006. Série C, N. 149. Disponível em: <http://www.corteidh.or.cr/casos.cfm>. Acessado em: 05.set.2016.

. Caso Gomes Lund y Otros ("Guerrilha Do Araguaia")

Vs. Brasil. Sentencia de 24 de noviembre de 2010. Disponível em:


<http://www.corteidh.or.cr/docs/casos/articulos/seriec_219_esp.pdf>. Acessado em 05.set.2016.

$\begin{array}{llllll}\text { de } & 1 & \text { de } & \text { septiembre } & \text { de } 2015 . & \text { Disponível em; }\end{array}$
<http://www.corteidh.or.cr/docs/casos/articulos/seriec_298_esp.pdf>. Acessado em: 05.set.2016.

DURKHEIM, Émile. Les Règles de la Méthode Sociologique. Paris: Alcan, 1956, $13^{\text {a }}$ ed.

FONDO DE LAS NACIONES UNIDAS PARA LA INFANCIA (UNICEF). Estado Mundial de La Infancia. New York, 2006. Disponível em: http://www.unicef.org/spanish/. Acessado em: 05.set.2016.

FREYRE, Gilberto. Casa-grande \& Senzala. São Paulo: Global, 2003, $48^{\text {a }}$ ed.

GARLAND, David. As Contradições da "Sociedade Punitiva": O Caso Britânico. Curitiba: Revista de Sociologia Política, nº 13, nov.1999.

INSTITUTO LATINO-AMERICANO DAS NAÇÕES UNIDAS PARA PREVENÇÃO DO DELITO E TRATAMENTO DO DELINQUENTE (ILANUD). Violência Institucional: Quando o Estado Agride a Criança. Disponível em: <http://www.unicef.org/brazil>. Acessado em: 05.set.2016.

KRIELE, Martin. Introdución a La Teoría del Estado. Tradução Eugenio Bulygin. Buenos Aires: Depalma, 1980.

MORELlO, Augusto M. Las Garantías Judiccionales para la Tutela Eficaz de los Derechos Humanos em Iberoamérica. In Instrumentos e Garantais de Proteção. Organização Flávia Piovesan e Maria Garcia. São Paulo: RT, 2011, Coleção Doutrinas Essenciais, volume. 5.

MOURA, Paulo Vieira de. Dimensões Éticas dos Direitos Humanos e o Regulamento Disciplinar da Polícia Militar do Estado da Paraíba. In Direitos Humanos em uma Época de Insegurança. Porto Alegre: Tomo Editorial, 2010.

ORGANIZACIÓN DE LOS ESTADOS AMERICANOS (OEA). Departamento de Derecho Internacional. Convención Americana sobre Derechos Humanos. Brasil. Reconocimiento de Competencia. Disponible en <http://www.oas.org/juridico/spanish/firmas/b-32.html>; Acceso el: 05.set.2016.

ORGANIZAÇÃO DAS NAÇÕES UNIDAS (ONU). Declaração Universal dos Direitos Humanos. Brasília: 1998. BR/1998/PI/H/4 REV. Disponível em: <http://unesdoc.unesco.org/images/0013/001394/139423por.pdf > Acessado em: 05.set.2016.

RICOEUR. Paul. O Justo 2: Justiça e Verdade e outros estudos. Trad. Ivone C. Benedetti. São Paulo: WMF Martins Fontes, 2008.

RIO. Josué Justino do/. O Direito Fundamental à Segurança Pública num Estado Democrático de Direito. Marília: Em Tempo, v. 12, 2013. 
SILVA, Paulo Napoleão Nogueira da. Direitos Fundamentais. São Paulo, 2008, IASP (Instituto dos Advogados de São Paulo), ano 11, nº 22.

WEBER, Max. Le savant et le politique. Collection 10/18. Paris: Plon, 1963.

WIEVIORKA. Michel. O Novo Paradigma da Violência. Tempo Social. São Paulo: Revista de Sociologia da USP, maio/97, 1997.

ZALUAR, Alba. Desarmamento, Segurança Pública e Cultura da Paz. Rio de Janeiro: Fundação Konrad Adenauer, Cadernos Adenauer VI, nº 3, outubro de 2005, p. 19-20. 